Revista Posgrado y Sociedad

Sistema de Estudios de Posgrado

Universidad Estatal a Distancia

ISSN 1659 - 178X

Costa Rica

revistaposgradoysoci@uned.ac.cr

\title{
Banana-Express: \\ Cinéma-Vérité del Pensamiento
}

Banana-Express: Thought's Cinéma-Vérité

Luis Fernando Fallas Fallas

Universidad Estatal a Distancia

San José, Costa Rica

Volumen 10, Número 2

Setiembre 2010

pp. $55-74$

Recibido: Junio, 2010

Aprobado: Agosto, 2010 


\title{
Resumen
}

La animación, en época reciente se ha transformado en una herramienta narrativa del documental. Con la ayuda de las nuevas tecnologías, interlocutores sin grandes financiamientos, pueden presentar su versión de hechos determinados. Su aplicación dinamiza nuevos espacios interpretativos y generadores de contenidos.

Palabras clave: documental, animadoc, narrativa cinematográfica, interpretación de textos.

\begin{abstract}
Animation, in recent times has become a documentary's narrative tool. With the help of new technologies, speakers, with small budgets, can present their version of a determined event. Its implementation triggers new interpretative spaces and content developers.
\end{abstract}

Keywords: Documentary, animadoc, film narrative, text interpretation. 


\section{Introducción}

Más allá de su soporte físico, el cine $\mathrm{y}$ el vídeo son una expresión audiovisual con una narrativa en constante cambio. Sus transformaciones en la expresividad técnica y discursiva son evidentes para la ficción. La no-ficción también presenta nuevas propuestas. Aún cuando el documental es visto primordialmente como una intercalación de entrevistados, imágenes captadas directamente de sucesos reales $\mathrm{y}$ en algunos casos recreaciones, sus capacidades expresivas y experimentales son mucho más diversas. Esto es de suma importancia para creadores y para espectadores.

En particular las instituciones educativas que centran sus fundamentos pedagógicos en una metodología a distancia, deben estar atentas a las variaciones y nuevas ofertas del documental. Debe cambiar la concepción del audiovisual como material complementario. Justamente gracias al impacto de las nuevas tecnologías, el documental, incluso con bajo presupuesto, es un texto autocontenido y capaz por sí mismo de tratar un tema cabalmente. Es decir, ser centro y motivador para la investigación, aprehensión o crítica de un objeto de estudio.

Desde el punto de vista creativo una variante del documental, el animadoc, le abre la puerta a los creadores a un mundo muy cercano pero difícilmente alcanzable por medio de la cámara. De hecho, se elimina la cámara como intermediario ineludible del proceso de realización. En esta modalidad se representa el universo de la interpretación. En el animadoc la referencialidad cambia y se limita a la posibilidad de corroborar los actos. Por lo tanto, sus dimensión figurativa geográfica deja de ser el elemento de narración visual por excelencia. Se favorece así un diálogo interpretativo, tanto a lo interno del animadoc como en la llamada de atención que hace sobre todos los demás recursos retóricos empleados por otros géneros documentales.

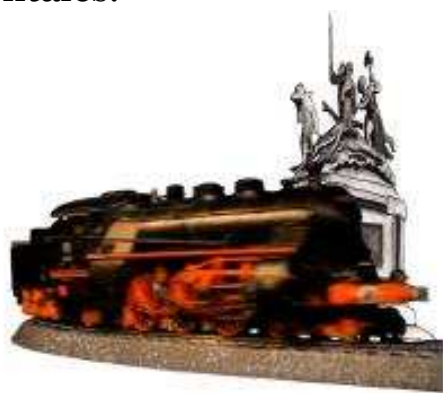

Figura 1. Banana-Express sintetiza gráficamente la visión del autor del impacto de la construcción del ferrocarril al Atlántico en la identidad costarricense.

Esta transparencia en la manipulación de la realidad permite al creador cuestionar lo representado y al proceso discursivo de toda obra audiovisual. Dicha dinamización de la criticidad es clave para la elaboración de materiales que inviten y provoquen en el público una respuesta activa a lo observado. Espectadores que se den a la búsqueda de información para ampliar o refutar lo propuesto por el realizador. De allí que se rompa el propagandismo y se fomente la creación de conocimiento. 
La UNED ya ha hecho su primer experimento en esta área. Como resultado presenta a la comunidad nacional el animadoc Banana-Express ${ }^{1}$ (Fallas, 2009). Sus características de producción invitan a reflexionar sobre las posibilidades de realización brindadas por las nuevas tecnologías. La obra nos ofrece una visión de la realidad imposible de capturar con una cámara.

\section{El Bioscopio}

El cine nació con el lenguaje documental. "En Inglaterra a la sala de cine se le llamó originalmente "Bioscopio" debido a su representación visual de movimientos reales de la vida (Del Griego bios, estilo de vida)" (Mcluhan, 1964, p.30). Por supuesto que se debe evitar la ingenuidad de considerar al documental como un retrato exonerado de una visión particular. Es una representación de los hechos.

Aquí, es clave para entender qué es un documental, el concepto de representación. Conlleva referirse necesariamente a la exposición de un suceso tangible, cargado de datos comprobables. Esta puesta en imágenes del hecho requiere que el mismo sea reelaborado. Son universos apartes lo acontecido y la manera en que se le expone a través de los medios. Su proceso de presentación requiere de volver a elaborar una cronología de los hechos, una selección de los elementos del mismo que se exponen, un punto de vista -físico e ideológico- sobre los mismos. Esta conjunción da a luz al documental: es fehaciente al hecho que

${ }^{1}$ Disponible en línea:

http://audiovisuales.uned.ac.cr/mediateca/vide os/122/banana-express.

Posgrado y Sociedad Vol. 10 No. 2 Año. 2010 presenta, pero al exponerlo lo representa mediante el proceso creativo de su realizador.

¿Por qué una interpretación? Esta característica se debe a la naturaleza misma de la realidad, que es compleja e inasible de manera íntegra. También se encuentran las limitantes técnicas para la captura y reproducción de lo grabado. Finalmente está el factor humano, último filtro de aquello que se registra y de cómo se reconstruye. Como creación humana está inevitablemente permeada por la subjetividad de su creador.

En la misma medida que se entiende al documental como un texto interpretativo, tiene la licencia de proponer su versión de los hechos echando mano a su reconstrucción, además de las imágenes captadas de manera directa y a la entrevista de los actores involucrados. Por reconstrucción se entiende: dramatizaciones, animaciones e ilustraciones. Todos estos elementos ficticios fueron adoptados $\mathrm{y}$ aceptados dentro del documental desde su génesis. Entre finales del siglo XIX e inicios del XX diversos noticieros en cine eran bastante populares. Dada la lentitud con que se transmitía la información y la escasa cantidad de cámaras disponibles, muchas veces los productores recurrían a soluciones creativas. "Reconstituciones y falsificaciones tuvieron un alto índice de "éxito". Imágenes genuinas memorables se recopilaron del terremoto de San Francisco de 1906, pero otras imágenes del evento, realizadas con miniaturas en maquetas, fueron igualmente aplaudidas" (Barnouw, 1993, pp. 25).

Justamente en esos años primigenios, la separación entre documental y ficción prácticamente ISSN 1659-178X 
no existía. El cine seguía siendo una especie de show de variedades o teatro filmado. No obstante, como herramienta de comunicación, se desarrollaba al lado de una industria mediática que ya para entonces era firme: los periódicos. Personajes como William Randolph Hearst, no tenían mayor reparo entre reportar lo ocurrido o inventarlo. Así, en el marco del inicio de la Guerra Hispano-CubanoEstadounidense, Hearst telegrafeó a su enviado a la isla: "usted proporciona las fotografías y yo proporciono la guerra" (Time, 1947).

Esta visión primó en la cobertura de la Batalla por las Colinas de San Juan, durante la guerra citada. Barnouw (1993) explica que en esa ocasión, los realizadores dramatizaron la batalla, pues para el gusto del productor, las imágenes reales del hecho no alcanzaban la pomposidad militar que habían relatado anteriormente los medios escritos.

"Nada tuvo de sensacional ni de espectacular. Jim y yo no supimos que habíamos participado en la célebre «carga» de la Colina de San Juan hasta que regresamos a Nueva York" (Agramonte, 1966, p.22), declaró años después Albert E. Smith, miembro del equipo de grabación en Cuba. Vitagraph, para congraciarse con las expectativas bélicas del público, reconstruyó y aumentó la violencia de los hechos. Es aquí, al introducir elementos de carácter dramático que se producen distorsiones muy conscientes de la realidad. Justamente el documental se hizo ficción. No obstante esta transformación se da de espaldas al público.
La desatención abierta al principio de documentalidad es ejemplar en el marco de ese conflicto bélico. El mismo equipo que registró la Batalla de las Colinas de San Juan iría aún más lejos para darle al público las imágenes exclusivas de la Batalla Naval de Santiago. Continúa Smith su relato, "cuando llegamos a Nueva York la ciudad hervía de entusiasmo a causa de las noticias de la victoria naval... Los reporteros nos preguntaron si teníamos fotografías de la batalla. -Claro que sí -contesté, embriagado por el triunfo del momento- claro que sí" (Agramonte, 1966, p. 23). La solución del equipo de grabación y de Vitagraph a estas imágenes inexistentes, fue montar una maqueta en una bañera, usar humo de cigarrillo y barcos en miniatura. De tal manera que una animación, sin apego alguno a los hechos, hizo las veces no de representación, sino de sustitución ante la audiencia de los sucesos acaecidos en Santiago. De ninguna manera hubo interés en declarar la naturaleza de imágenes creadas ex profeso. Tampoco de parte de la audiencia hubo capacidad para saberse frente a un truco de efectos especiales.

Bajo esa particular visión de lo informativo se rompe lo que se podría denominar la "documentalidad del documental". Primero, los hechos al ser recreados no respetan el principio de referencialidad, pues su recreación no es fiel al hecho representado. Segundo, se oculta deliberadamente su naturaleza de puesta en escena. Por lo tanto la utilización de estas ayudas para la visualización no cumplían con la 
fiabilidad necesaria para considerárseles válidas dentro del género de no-ficción.

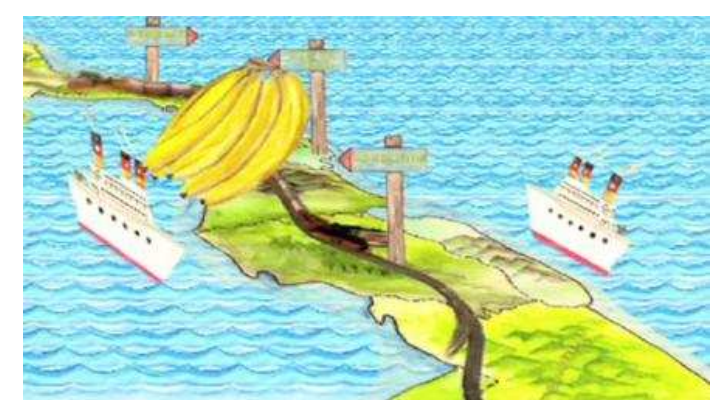

Figura 2. Las compañías bananeras fueron propietarias de ferrocarriles en toda la región centroamericana y de una flota de buques de carga. Aunque la propuesta visual de BananaExpress no refleje con exactitud la distribución de las líneas, su referencialidad como hecho histórico comprobable es irrefutable.

Es delicada la línea entre la distorsión y la interpretación de la realidad. Se podría decir, en casos como la Batalla por las Colinas de San Juan y la Batalla Naval de Santiago que está en el ámbito de la interpretación argumentar si los estadounidenses eran héroes liberadores u oportunistas. Estas dos posiciones, u otras más, se pueden construir a partir de diversos datos comprobables, verídicos. Pero inventar imágenes de las batallas con enfrentamientos que no se dieron, entra en el ámbito de la creación ficticia de elementos narrativos, máxime cuando no se advertía sobre su utilización. De tal manera que ahí es donde se da un divorcio con la ética del documental.

Se puede revisar la diferencia con lo hecho por Flaherty en Nanuk, el esquimal (1922). Es conocido que el autor solicitó de manera expresa a los inuits realizar actividades de una manera arcaica. En algunos casos los mismos indígenas sugirieron algunas de las proezas. Una de esas famosas secuencias es la cacería de morsas. Los

Posgrado y Sociedad Vol. 10 No. 2 Año. 2010 inuits ya contaban con armas de fuego para el momento de la filmación. Sin embargo, llevaron adelante la caza de la manera tradicional con arcos y arpones, poniendo en riesgo sus vidas. Otra creación exclusiva para la cámara es la del igloo en que duerme la familia de Nanuk. Esta edificación fue modificada para permitir la entrada de más luz y albergar al equipo de filmación.

Lo retratado por Flaherty no dejaba de tener una referencialidad directa y comprobable con la realidad. Los inuits, en efecto cazaron morsas de la manera en que se presenta en el documental y también dormían en igloos. Es decir la información dada era veraz aunque su representación fuese motivada por la presencia de la cámara.

La diferencia entre Nanuk, el esquimal y la Batalla por las Colinas de San Juan, es que Flaherty se apoyaba en hechos comprobables para su representación. En su deseo de retratar fielmente la lucha del inuit con las fuerzas inclementes de la naturaleza, reconstruye sus momentos más álgidos. Por el contrario, en la Batalla por las Colinas de San Juan, simplemente se quería satisfacer la expectativa generada por otros medios de difusión. Para representar el heroísmo de las huestes estadounidenses se genera una ficción sobre un hecho real. Ahí reside la diferencia: se ha menoscabado el compromiso del documental con la veracidad de lo representado, con su referencialidad.

Justamente navegando en ese margen de referencialidad se encuentran todas las reconstrucciones y demás trucos utilizados por los documentalistas. En este particular cuentan los documentalistas con una ventaja, si bien deben ser veraces en su representación de los hechos, se salvan de la verosimilitud de los ISSN 1659-178X 
mismos. En la ficción, explica McKee, las coincide-ncias tienen poca tolerancia en los mundos ficticios, que en pro de su verosimilitud deben crear realidades consistentes (para.). En cambio, la licencia poética del documentalista es su apego a la realidad. iCuan sorprendente es que una abeja pueda ir de una flor a otra y llevar en sus patas minúsculas partículas que polinicen a la siguiente y sin embargo este es un hecho comprobable, verídico!

Muchas veces la realidad se torna más surrealista que la propia ficción. Es en este nicho que los documentalistas buscan maneras más fehacientes de retratar la realidad. Las imágenes captadas de un suceso puede que no satisfagan la percepción que del hecho tiene el creador. Se busca entonces una solución, una herramienta técnica y narrativa que le permita al documentalista expresar su particular mundo interpretativo.

\section{Cinéma-Vérité del Pensamiento}

En su aproximación a los diversos espacios y tiempos de la historia, el documental ha tenido que ensayar con diversas técnicas. Se establece una interacción entre el entorno y la percepción del creador. El resultado final será la expresión de la realidad como es observada por el documentalista. Este proceso de subjetivización no es evidente. En particular el recurrir a elementos referenciales directos o al menos tangibles de los hechos, lleva a que el género se cubra de una falsa objetividad. El castillo medieval es el castillo que se presenta en la imagen. El entrevistado expresa lo que se le escucha decir.
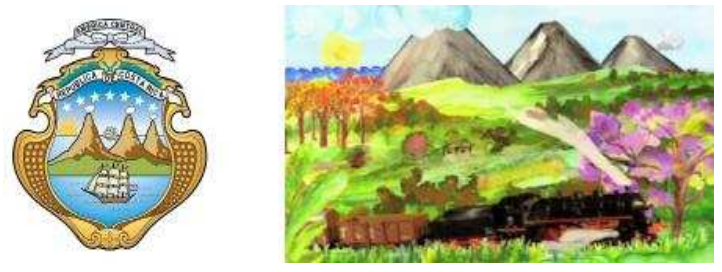

Figura 3. En la comparación del escudo nacional con la su versión en el animadoc, se ve el proceso de apropiación del autor de BananaExpress del mundo que le rodea. Es la cámara en la psique del realizador.

Esa sensación de no mediación entre el objeto y su representación audiovisual, está profundamente intervenida. El documental es la interpretación del hecho por parte del realizador. El documentalista expresa sus proceso de subjetivización del mundo percibido a través de la captura de elementos comprobables del mismo. En ese proceso de captura los altera al punto de personalizarlos.

La animación es una herramienta descriptiva harto conocida dentro del documental. Mapas, procesos y mecanismos, se visualizan a través de esta técnica. En la celebrada serie de Frank Capra, Por qué peleamos (1942-1944), los "mapas animados, hechos en los estudios de la Disney... aportaron poderosos momentos" (Barnouw, 1993, p. 158).

No obstante no es Capra el primero en utilizar el recurso de la animación. A inicios del siglo XX, un caricaturista descubre las posibilidades editorialistas de la animación en el cine. Si se toma en cuenta que aún actualmente sigue siendo común para el medio escrito intercalar, en la 
sección de opinión, artículos con caricaturas, se entenderá que fuese justamente de un dibujante que nació la idea de aplicarlo a este género. Aparece así el primer documental animado o animadoc. En El hundimiento del Lusitania (1918), su realizador, McCay, utiliza animación para recrear el torpedeo de un barco en altamar, sin alterar la veracidad de los hechos. El Lusitania era un barco de pasajeros y fue torpedeado por un submarino Alemán. El pánico cundió entre los pasajeros conforme el barco se hundía.

Dicha referencialidad a lo factual en nada niega que el documental tome partido para apoyar la intervención estadounidense en la Primera Guerra Mundial. Es cierto que no relata sobre el trasiego de armas que se daba entre Estados Unidos e Inglaterra. Sin embargo su falta de contextualización no le resta veracidad al hecho que representa. La forma en que se presenta el suceso, ayuda a fortalecer la posición intervencionista, pero esto se consigue por medio del manejo del discurso y no de la distorsión de los hechos comprobables.

Hay un elemento aún más importante en cuanto a la utilización de la animación como insumo para el documentalista. En ningún momento se podrá pretender que el espectador asuma las imágenes como una transferencia directa de la realidad. La exposición por medio del dibujo animado deja claro que se trata de la interpretación de un hecho. Esto refuerza la conceptualización del animadoc como un psico-documental, o si se quiere, el cinéma-vérité del pensamiento. La dinámica que se propone extrapola a la cámara discreta, esa que pasa desapercibida, que pretende captar sin distorsionar lo captado, o que representa los espacios Posgrado y Sociedad Vol. 10 No. 2 Año. 2010 como son y no iluminados para su mejor fotografía; en el animadoc se representa de manera directa la impresión de la realidad en la psique del autor. No depende aquí del histrionismo de actores en una ficción, tampoco se adecua un ambiente a las necesidades cinematográficas. No es un director interpretando un guión o ilustrando la experiencia de un tercero. Es la representación fehaciente de cómo el mundo impacta la sensibilidad del autor. Es la visualización del proceso de interpretación, es la cuestión sobre qué es la verdad.

La diferencia con el cine ojo de Vertov, que capta el mundo como sólo una máquina lo puede ver (para. Barnouw, 1993), es que en el animadoc, el ojo se vuelve hacia dentro y capta un mundo que solo una persona puede ver, el mundo interpretativo de su creador. Esas imágenes particulares que se construyen en su psique.

Uno de los objetivos de BananaExpress, como de cualquier animadoc, es filmar ese espacio psicológico. El resultado de este ejercicio, más que una representación de la realidad factual, es una radiografía de la realidad pensada por el creador. A diferencia del documental hecho con imágenes captadas de los hechos, las reconstrucciones pictóricas conllevan una interpretación incluso de los elementos que constituyen la imagen representada. No se expresa una arista de lo ocurrido, se retrata la íntima interpretación del mundo de una persona, o de ser el caso, de un conjunto de personas involucrado directamente con la realización del documental. 


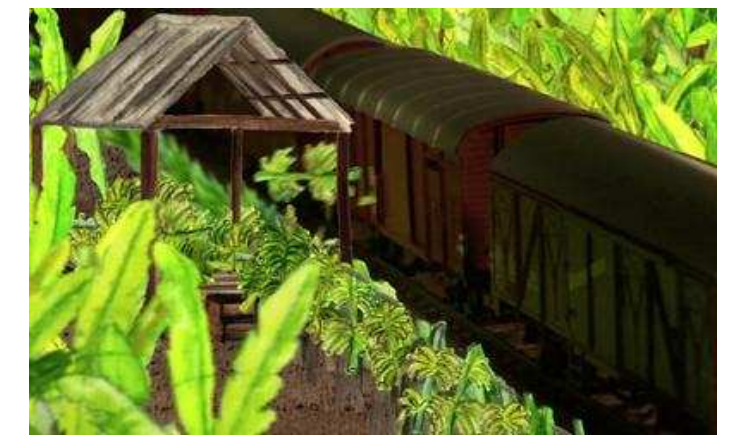

Figura 4. Banana-Express expresa la realidad interpretada por el realizador. Esta es su apreciación del hecho real, nunca pretende sustituirlo.

Siguiendo la clasificación de Nichols (1991), "en el film documental, cuatro modos de representación se destacan como patrones de organización dominantes alrededor de los cuales la mayoría de los textos están estructurados: expositivo, observacional, interactivo y reflexivo" (p. 32). Según el autor, un documental expositivo es aquel que presenta al realizador como un conocedor absoluto que abre una ventana a una realidad lejana. Desde una distancia segura, la obra narra lo que le acontece a terceros y la opinión dada por el documentalista se presenta como única e infalible. Se supone en este proceso que el creador no cuestiona lo que ocurre, simplemente se expone lo que la cámara capta.

El documental observacional intenta invisibilizar la presencia del director o su influencia en lo representado. Guarda rigurosa fidelidad al tiempo real de las acciones y se reniega del impacto que puede causar la grabación de un hecho en su propio desenvolvimiento. No obstante, esta intención de que la realidad se narre a sí misma, se quiebra cuando el producto pasa por el proceso de edición, cuya responsabilidad recae en el documentalista. Incluso en el acto mismo de la grabación, la subjetividad del creador queda expuesta a lo interno de la imagen: selección del emplazamiento y encuadre de la cámara y en la discriminación respecto a qué se filma y qué se excluye de la grabación.

El documental interactivo explo-ta la influencia que generan autor y cámara en la realidad filmada. Aquí, una herramienta clave de la narración es el hacer un documental. Es una obra dialógica donde el elemento filmado interactúa constantemente con su creador. Hace poco hincapié en el impacto de esta interacción, y más bien se concentra en el resultado de la misma. Es decir se centra en los resultados de intervenir a través del documental una realidad dada, más que cuestionar los procesos interpretativos.

Las obras reflexivas, como Banana-Express, gravitan sobre los procesos de manipulación e interpretación de la realidad representada. Exponen su tema en particular y a la vez cuestionan la subjetivización por la que atraviesan todos los demás documentales. Así explotan una narrativa interna y una intertextualidad con el mundo del documental. No pretenden generar un narrador cuasiobjetivo, son obras claras y frontales respecto a su subjetividad.

Si bien no todos los documentales reflexivos son animaciones, sí todos los animadocs son, primordialmente, documentales reflexivos. BananaExpress tiene prístina franqueza de ser una visión de la realidad. Dada su naturaleza de imágenes conceptualizadas por medio de dibujos, es 
inevitable que el público las asuma como interpretaciones, sustituciones del hecho concreto, existentes exclusivamente en el universo del animadoc.

Este ambiente visual creado del animadoc, genera que la obra además de tratar sobre un hecho en particular, también necesariamente lidie con el concepto de interpretación. Esta interacción, común a la creación de cualquier documental, tiene su particularidad en la frontalidad con que se presenta en el documental animado.

El animadoc desarrolla un ejercicio de franqueza con el público, ya que la técnica representativa evidencia la manipulación subjetiva de la información referencial. Así se remite directamente a la reflexión paralela sobre cómo la interpretación atraviesa transversalmente todo documental. Se pretende evidenciar que el animadoc es la opinión y visión sobre un aspecto dado del mundo que rodea $\mathrm{u}$ afecta al realizador. Además, supone que el ejercicio incita al espectador a pensar $y$ repensar las dinámicas de elaboración de todos los otros productos documentales que se le presentan bajo otras modalidades, como falsamente objetivos.

$\mathrm{El}$ animadoc es un documental que recrea directamente las impre-siones que deja el mundo en la mente del artista y no en la película de una cámara. Esta posibilidad llama a un nuevo diálogo de la interpretación.

El animadoc exige el abandono de la ingenuidad frente a los productos audiovisuales, en particular los documentales, para re-concebirlos como obras partidarias y parciales sobre el mundo que nos rodea. Es cortar la relación directa, implícita, creada por otras modalidades de documental, sobre la referencialidad no Posgrado y Sociedad Vol. 10 No. 2 Año. 2010 intervenida entre la representación y el acontecimiento.

La fiabilidad de la imagen transmitida por el documental es una condición sine qua non de su género, al igual que su utilización para la creación de un sentido particular independiente de su referencialidad. En esta última parte de la ecuación documental se construye el animadoc. $\mathrm{Al}$ romper con la referencialidad al mundo concreto, pretende centrarse en los procesos interpretativos. Así el animadoc se inscribe como documental reflexivo, una corriente iniciada en las primeras décadas del Siglo XX por Vertov. Los autores Bordwell y Thompson (1997) se refieren a uno de los documentales de ese director, El hombre con la cámara de cine (1929) en los siguientes términos: "El film se convierte en una celebración del poder del documentalista para controlar nuestra percepción de la realidad a través de la edición y los efectos especiales" (pp. 415-416).

Al igual que la obra de Vertov, el animadoc cuestiona el proceso de elaboración de sentido. Además tiene la posibilidad de presentar esa realidad tan íntima como la construcción que produce en una persona la realidad sentida, referida o vivida. Se toman prestadas las posibilidades hiperbólicas de la animación para generar metáforas $\mathrm{y}$ acciones que logren retratar las conexiones únicas que se generan a nivel cerebral. Se podría decir que es una representación de la sináptica de los mundos individuales. Aquí la intención del documentalista se une con las posibilidades técnicas de la animación, "No hagas lo que una cámara puede hacer - haz lo que una cámara no puede" (Williams, 2001, p. 16). El animadoc entra en el proscenio del pensamiento y a ISSN 1659-178X 
diferencia de lo que hace Vertov en su documental, no se truca el mundo real, se crea uno nuevo; una realidad percibida.

Vals con Bashir (2008) de Ari Folman, es el primer largometraje animadoc. Su técnica le permite al director retratar el estado mental de la amnesia y el complejo camino para vencerla. La reconstrucción remite más a un viaje mental que a uno físico. La animación consigue reconstruir la naturaleza de segmentos impactantes pero desconectados entre sí, el ambiente de pesadilla, ese anárquico espacio de la inconsciencia donde el tiempo y espacio dejan de tener sentido y se mezclan. Se encuentran en el documental el sueño y la animación, dos hipérboles de la realidad que en su unión reconstruyen el trauma de un joven soldado.

Esta obra es en particular ejemplarizante del campo mental que es capaz de retratar la animación. El trauma psicológico es representado con elementos animados y justo en el punto en que se separa la experiencia personal del hecho histórico, el documental recurre a la imagen de archivo. Quiere con esto el director dejar en claro que, más allá de la pesadilla, de su subjetividad, la matanza con que culmina su relato es un hecho verificable. La interpretación de la misma queda a la opinión de cada individuo pero no cabe espacio para la negación de la masacre en los campos de refugiados de Sabra y Shatilla en el marco de la invasión israelí a Líbano en 1982. Siguiendo la lógica del documental reflexivo, delimita claramente el ámbito de la referencialidad factual del de la interpretación.

\section{Banana-Express}

En el año 2009 el Programa de Producción de Material Audiovisual de la UNED realiza un animadoc. BananaExpress (2009) es una aproximación a los conflictos generados en Costa Rica y Centroamérica tras el establecimiento del ferrocarril al Caribe. El proyecto se realizó en el marco de la Maestría en Producción de Medios de la Universidad de Ciencias Aplicadas de Ostwestfalen-Lippe.

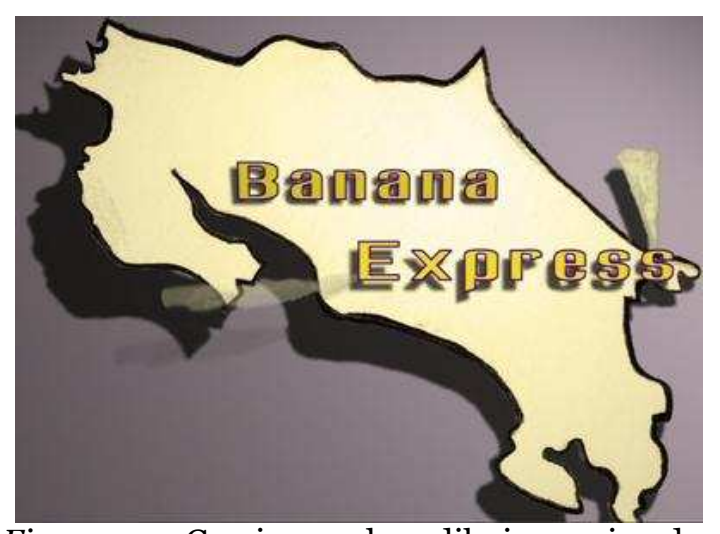

Figura 5. Gracias a los dibujos animados mezclados con el documental, desde Alemania se produjo un material que viaja por la historia del ferrocarril en Costa Rica y su impacto local y regional. Banana-Express es un animadoc que como cinéma-vérité del pensamiento se libra de las limitaciones espacio-temporales.

Desde tierras germanas, el realizador Luis Fernando Fallas, se aproximó a una realidad espaciotemporal distante. Este es un valor agregado de la aplicación de la animación al documental. Claro que no es una implementación novedosa. Lo que ha cambiado es el nivel de complejidad técnica requerida para 
su elaboración. Banana-Express, un documental corto de 6 minutos de duración, contó solo con el trabajo de una dibujante y un animador. Se prescindió de la utilización de cámaras para la captura de los diferentes dibujos. Las ilustraciones fueron digitalizadas mediante un scanner $\mathrm{y}$ posteriormente manipuladas en un ordenador.

El ojo de Vertov, como se anotó antes, se vuelca hacia dentro y al perder la intermediación de la captura física de imágenes tiene la puerta abierta al imaginario humano. El documental liberado de la materialidad, es pura interpretación, pero conserva siempre en su argumentación la necesaria rigurosidad con el hecho real.

La democratización de la creación audiovisual ha sido posible gracias al avance y abaratamiento de las herramientas de trabajo. Esto por cuanto ya no se requieren de presupuestos prohibitivos y gran cantidad de personal para lograr un producto con calidad profesional. Los grandes equipos de antaño se sintetizan en sistemas de escritorio e incluso portátiles con costos alcanzables para una generalidad importante de actores sociales. Se pone así esta técnica narrativa al alcance de pequeñas productoras, como es el caso de universidades y grupos independientes.

En Banana-Express, la intención del autor es relatar de manera sincrética un proceso prolongado que abarca múltiples territorios y del cual además no existen imágenes de archivo. Hay que tomar en cuenta que la construcción del ferrocarril al Atlántico en Costa Rica, se inicio en 1871. De tal manera que siquiera hay algunas escasas fotografías de este proceso. No obstante el animadoc pretende representar la forma en que los hechos Posgrado y Sociedad Vol. 10 No. 2 Año. 2010 son interpretados por el documentalista. Es más, en la caracterización de los mismos está implícita su crítica.

El animadoc requiere de que contenido y forma sean complementarios. Dicha dinámica no es exclusiva de esta variedad del documental, pero si conlleva un elemento adicional; pues ya no sólo se trata de angulación, temperatura de color y texturas, sino de la propia construcción de los elementos dentro de la imagen. Se supera el universo de la composición como generador de sentido y es ahora la reelaboración de la imagen desde cero la técnica significante por excelencia.

$\mathrm{Si}$ algo novedoso brinda el uso de la animación como recurso narrativo primordial del documental, es justamente la extrapolación de más elementos de la ficción. El documentalista adquiere control total del mundo que reconstruye. No depende de actuantes externos voluntarios, ni de cuan oportuna sea su presencia en determinado lugar, o del impacto que genera una grabación en el suceso registrado. Estas realidades creadas se ajustan al detalle al deseo del autor. Sin restarle a la fidelidad con los hechos, se genera un proscenio completamente manipulado.

En Banana-Express la capacidad de diseñar la realidad narrada es en parte responsable de la síntesis que se realiza. Esto por cuanto permite mezclar en una misma secuencia de hechos, tanto el proceso de corta, carga y exportación del banano; como el relato de la construcción de la línea férrea. Esta unión a su vez genera nuevas comparaciones y figuraciones, que se pretende, ayuden a una mejor comprensión del impacto de la dinámica del enclave en las poblaciones centroamericanas.

ISSN 1659-178X 
El contrapunto fáctico para la elaboración animada de las impresiones del director, está en los textosentrevista seleccionados, con que discurre el animadoc. Los mismos, recuentos históricos de la opinión que generaba en distintos momentos la presencia de la transnacional bananera, son el ancla de la documentalidad de la obra. Con este elemento el autor dilucida, más allá de su percepción de la dinámica económica global, la importante polémica generada en la sociedad costarricense por la construcción del ferrocarril y el comportamiento de la compañía bananera.

Cabe rescatar como otro elemento significativo que la dibujante era de la provincia de Limón y los parajes que debía reproducir, por lo tanto, le eran familiares. De forma que inclusive, en la materialización de las imágenes, también se da un proceso de entrevistaartística. El creador del animadoc aún requiere de intermediaciones para plasmar su pensamiento. De toda suerte que Banana-Express sea una obra colectiva, en que la secuencia final de elementos visuales son el resultado del aporte de múltiples voces. En esto, el proceso de elaboración reproduce a la misma realidad, donde lo que existen son versiones y lo que concebimos como realidad no deja de ser una selección de dichas posibilidades.

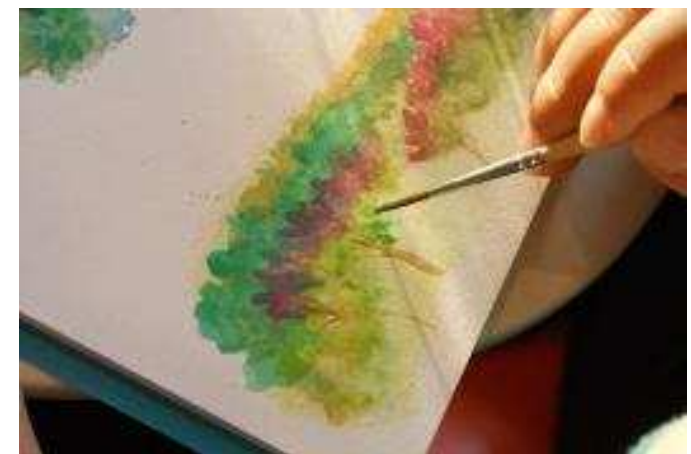

Figura 6. Las imágenes, creadas sobre papel, brindan una textura mucho más orgánica. Así se aleja del proceso digital y se acerca al de la imaginación. Coinciden para mejor efecto de Banana-Express técnica y aspiración artística.

\section{Banana-Express es una} aproximación al cinéma-vérité del pensamiento, pero no su concreción purista. Sí es estricto con el respeto a su referencialidad a pesar de su subjetividad. De manera clara presenta hechos y los diferencia de su acción interpretativa.

Adicionalmente la obra en cuestión se presenta como ejemplo del impacto de las nuevas tecnologías en la dinámica de producción. La posibilidad de realizar una obra con calidad profesional con herramientas de bajo costo y con un personal mínimo, son posibles gracias al abaratamiento de los equipos. Este factor, meramente técnico, es promotor de la democratización y de la pluralidad de voces expresivas. Se logran derribar barreras técnicas y se permite la convivencia de discursos sin que el punto de la calidad en que se presentan genere distorsiones o exclusiones.

En un ambiente en el que se vislumbra que el grueso del trasiego de información en Internet será mediante el vídeo. De acuerdo a los datos de CISCO (2010), para 2014 un 91\% de 
todo el material que se consume en la red será alguna forma de vídeo. El reducir la brecha entre grandes y pequeños productores, garantiza una exposición más equitativa de los materiales ante un público o audiencia que a su vez tiende a ser más exigente de la calidad (en fondo y forma) de lo que consume.

\section{Cine en casa}

El proceso de producción de Banana-Express combina lo conceptual con lo netamente práctico. Por un lado el grueso de la dinámica de realización se llevó a cabo en casa, rodeado de la familia. Este espacio se transformó en un taller de trabajo. La ilustradora se encontraba en constante funcionamiento, lo que permitía al director afinar detalles del dibujo en el momento. La dibujante a su vez, aportaba a la composición final de los cuadros. Era así un proceso colaborativo de la representación del mundo percibido por el director.

De manera esquemática, el proceso productivo, empezó como cualquier obra profesional con una investigación sobre el papel de las bananeras en Costa Rica en particular y en la región centroamericana en general. El resultado de la misma da paso a un guión. Posteriormente se hace un desglose de los planos que se pasan a un storyboard. Seguidamente se hace un plan de rodaje y se procede a la grabación en estudio y locación.

La grabación en estudio consistió de un tren a escala y una actriz, ambos sobre fondo verde. Esto permitiría más tarde suprimir el fondo e integrarlos con otros elementos gráficos. En locación el trabajo se llevó a cabo exclusivamente con la actriz. Para esta tarea se requirió de un equipo de seis personas, además de la actriz. Hasta aquí la dinámica de producción no se separa mayormente del común de la industria, más allá de un reducido presupuesto.

El impacto de la tecnología en la dinámica de producción ya se deja ver en la grabación como tal. Con la utilización de una cámara digital Panasonic P2 con un adaptador de $35 \mathrm{~mm}$, a un costo ínfimo, el material filmado logra tener calidad cercana a la del celuloide. Sin embargo, la mayor incidencia de la nueva accesibilidad a las herramientas productivas de bajo costo con calidad profesional, se da en el proceso de animación.

Ante todo se prescindió de utilizar acetatos (superficie transparente para pintura) ya que se deseaba explotar la textura del papel y el proceso de escaneo y digitalización de la imagen permitía pintar en fondos opacos y aún así generar una composición multicapas. Aquí es importante señalar que efectivamente no fue una cámara de vídeo o cine la que captó los dibujos, sino un simple escáner casero, a una muy buena resolución, el responsable de la digitalización del material. Así con el advenimiento del desarrollo tecnológico, incluso la cámara deja de ser intermediaria en el proceso de captura de imágenes, lo cual baja aún más significativamente los costos.

Las imágenes escaneadas, eran luego "limpiadas" en PhotoShop. Esta limpieza consiste en librar al dibujo del fondo en que se pintó. Se conserva la textura del papel y a la vez se cuenta con un canal alpha. Esto es justamente lo que permite superponer las imágenes en una composición reconstruyendo un espacio que simula tridimensionalidad. 

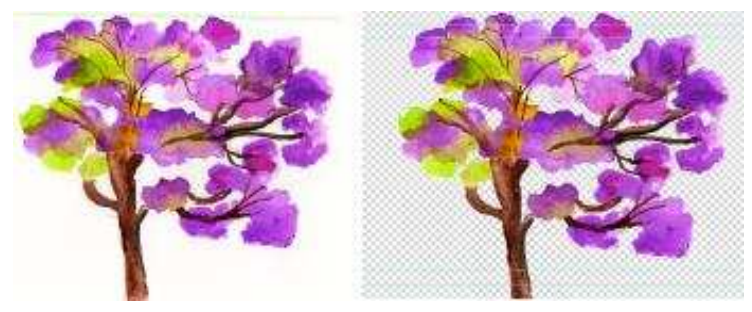

Figura 7. La imagen antes y después de la "limpieza" de su fondo en PhotoShop. El cuadriculado equivale a espacio transparente. Este canal alpha permitía luego la composición de varias imágenes en un espacio que imita la tridimensionalidad.

Esta composición es justamente el trabajo que se realizaba inmediatamente en AfterEffects. En este software las imágenes se integran como en un escenario o diorama. Al contar con los distintos elementos escénicos por separado se facilita la animación de alguno de ellos lo que brinda una mejor sensación cinética a la composición final. Esto a su vez facilitaba la integración con elementos grabados en directo, como es el caso del tren de a escala.

Hay que hacer una pausa en este punto para indicar que el estilo de animación aplicado también tenía en mente el ahorro de recursos. Es decir, no se pretendía un movimiento de los elementos en pantalla de tipo clásico, Walt Disney. Por el contrario, dada las limitaciones en tiempo y personal, se optó por modificar los ejes de los elementos de pantalla para simular movimiento. En otros casos, con la ayuda de las máscaras en AfterEffects, se recreaba la sensación de cambio en las imágenes. Este es el caso en particular del humo del tren, que consiste en una serie de no más de 10 imágenes que se suceden mediante máscaras animadas.

Ambas aproximaciones requieren de un tiempo de trabajo mucho menor que la animación tradicional. Además de que el software genera por sí mismo los puntos medios necesarios para lograr el movimiento del objeto. En más detalle, cuando se recrea movimiento con animación cuadro a cuadro, por cada segundo en pantalla se requieren de entre 12 y 24 diferentes dibujos de un mismo objeto para recrear el movimiento. Ya con la técnica alternativa utilizada, fueron necesarias 251 distintas ilustraciones. Era, para el equipo de trabajo, imposible considerar la animación tradicional. La tecnología disponible y la técnica seleccionada permitía con un número considerablemente reducido de dibujos, simular convincentemente el movimiento.
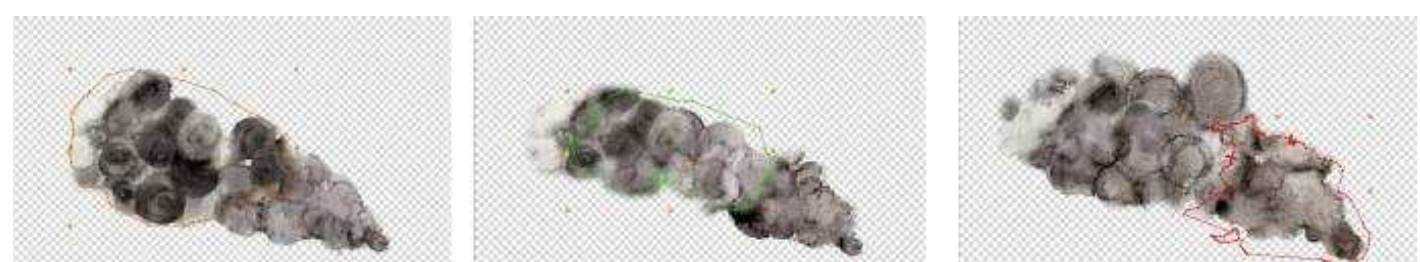

Figura 8. Ejemplo de animación usando máscaras. Una imagen se desplaza por encima, secciones en naranja, verde y rojo, simulando movimiento. Esto permitía que un mismo dibujo permaneciera hasta 3 segundos de pantalla, esto es un importante ahorro de recursos comparado con la animación tradicional. 


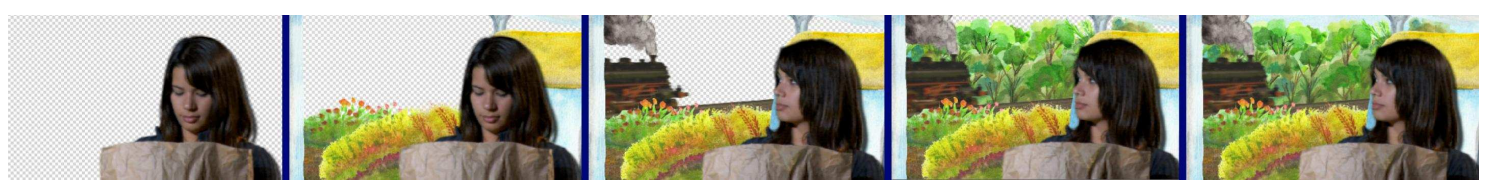

Figura 9. Proceso de composición de la imagen por capas. Elementos de la grabación en directo se integran con los dibujos para crear un proscenio que refleja el mundo percibido por el creador de Banana-Express.

En AfterEffects, por ejemplo, una vez que las imágenes tenían partes móviles, a las mismas se les indicaba el punto de arranque y el final, mientras el software calcula todos los puntos intermedios. Esto ya es un ahorro sustancial de esfuerzo. En BananaExpress, donde el director era además animador, se fortalece la posibilidad de este animadoc como cinéma-vérité del pensamiento. Manejo de cámara y composición de la imagen responden a la concreción directa de la visualización del creador. La posibilidad de recrear el deseo expresivo del director está exclusivamente limitado por sus posibilidades de manejo técnico.

Una vez recreado el proscenio, se manejaba como un escenario real, controlando las cámaras virtuales para conseguir las angulaciones y movimientos deseados. El resultado de la aplicación de esta técnica es similar al de películas clásicas como Mary Poppins (Stevenson, 1964). La diferencia es que en el caso de Banana-Express no media un ejército de trabajadores para la concreción de la obra.

El advenimiento de las nuevas tecnologías no convierte al género en un formato casero. El profesionalismo, como elemento clave para producir un material de alta calidad sigue siendo esencial. Existe la división de labores, solo que las plataformas de trabajo digital han favorecido la convergencia de algunas de estas labores. En este particular, Walter Murch, explica que una vez que empezó a editar en sistemas no lineales se percató de que Posgrado y Sociedad Vol. 10 No. 2 Año. 2010 "los editores de filmes debían de empezar a pensar verticalmente también, lo que quiere decir: ¿Qué puedo editar dentro del cuadro?" (2001, p. 130). Esto porque justamente la manipulación de la imagen captada dejó de requerir de un gran equipo de diferentes técnicos capacitados en el uso de complejas herramientas. Ahora en una misma computadora es posible hacer trabajo de edición, animación y manipulación cromática de la imagen.

Esta simplificación de los procesos productivos a su vez favorece la creación de obras más intimistas. En las mismas, como se apunta, no se niega el proceso formal productivo. Pero una interacción más directa del creador con el material expresivo conlleva a una mayor apropiación. En Banana-Express, la forma en que ambientes y dinámicas se expresan serían imposibles en una grabación en directo. El recorrido geográficohistórico responde más a la impresión que documentos científicos, arte y vivencias han dejado en el realizador que a las características específicas del entorno reproducido.

El animadoc nos presenta las bananeras imaginadas por el director. Nos lleva en un recorrido por su mundo interpretativo. La cámara a esta experiencia, sólo la podía manipular él, era su realidad particular. Es más, dada la participación de una dibujante, es el cinéma-vérité del pensamiento de ambos, su Limón-imaginado. Esta característica le da a la obra además una dimensión poética que la acerca 
en su dimensión humana al espectador. Es incluso su sistema de producción una alternativa a la dinámica económica que denuncia la obra. Ante la automatización y la creación en serie, la masificación de toda la actividad humana, la particular aplicación tecnológica en BananaExpress rescata el valor de la obra artesanal. Es el sétimo arte visto más en su intimidad, desligándose de la gran industria hollywoodense. Esta humanización del lenguaje audiovisual augura que la avalancha de información en la Internet pueda llegar a verse más como una comunidad y no tanto como un alienante comedero mediático.

Para el ambiente educativo, como se apuntó, primero permite garantizar que sin erogaciones millonarias, habrá posibilidad de crear materiales competitivos con el entorno en que deben de insertarse. Esto es clave para lograr una actitud positiva del estudiantado. Máxime cuando se conoce que "El aprendizaje informal y su corolario, aprendizaje incidental, son las formas predominantes del aprendizaje de los adultos (Marsick y Watkins, 2001). Los adultos escogen qué, dónde y cómo desean aprender y usualmente son los evaluadores de su propio aprendizaje" (Heuer, 2007, p. 56).

Los sistemas educativos, por ende, deben procurar que sus materiales sean relevantes no sólo porque son evaluados, sino porque tienen posibilidad de encantar a su usuario. Esto favorecerá a su vez, ante todo bajo los principios de la UNED, llegar con sus materiales didácticos a la población general y generar una competencia real a la oferta mediática comercial imperante en el país.

En un paso posterior, otra ventaja que ofrecen los sistemas de producción de bajo costo es modificar sistemas de evaluación cuantitativos por otros que fortalezcan los procesos de creación del conocimiento. Las instituciones educativas podrán dar espacio a sus alumnos, quienes con un manejo elemental de ciertas herramientas de edición y composición darán videorespuestas a los problemas planteados en sus asignaturas.

Mary Hanley, fomenta en sus alumnos el escribir poesía como proceso de evaluación al curso que imparte. Las obras de los estudiantes a su vez se convierten en objeto de estudio. "El proceso creativo nos permite compartir nuestro ser cultural y representar nuestras identidades y nuestra lucha común por voz y creación de sentido" (2007, p. 42). En el caso del vídeo esto permitiría compartir una visión del entorno del estudiante y de sus objetos de estudio que ya no sólo estaría expuesta a sus compañeros, sino que se convertiría en una memoria institucional sobre el contexto en que se encuentra.

Un proceso como este lo que preconiza es que la tecnología podría acercar a muchas más personas a un papel activo en la creación de conocimientos. Se podrían generar redes plurales de opinión o espacios atemporales de estudio. Bien podrá la universidad investigar y generar aplicaciones novedosas para un movimiento documental de base, por así decirlo. Es decir, podrán transformarse en espacios de creación formal de narrativas 
audiovisuales y a la vez en contenedores populares. Serán espacios de confluencia y no de separación.

Banana-Express es una primera experiencia, tímida si se quiere, por tratarse de un corto. Pero en seis minutos, la confluencia digital y esquema de trabajo, hicieron posible expresar el impacto ambiental, político y perspectiva histórica de la construcción del ferrocarril en Costa Rica. Es a su vez un cinéma-vérité del ámbito interpretativo del creador, pues nos presenta esos procesos enmarcados en su particular conceptualización. En este ejercicio de opinión no pierde la referencialidad. Permite de esta forma evaluar también el proceso de subjetivación, al ser el mismo evidente por la naturaleza animada del producto.

\section{Conclusión}

Las posibilidades narrativas $\mathrm{y}$ argumentativas del lenguaje audiovisual, con el animadoc, se afianzan aún más en su reconocimiento como textos plenos. No se trata de materiales de apoyo a otros, aunque como cualquier otra creación humana, se enriquecen de lo que les rodea, de su potencial intertextualidad. Son obras autocontenidas, que generan sentido desde su propia delimitación.

No hay temáticas vedadas al lenguaje audiovisual. Lo que existe es un reto para su presentación. Lo que puede privar para su escogencia como material didáctico son valores de idoneidad económica o pedagógica. Las nuevas tecnologías han venido a reducir el rol de las consideraciones económicas. El trabajo interdisciplinario y la investigación permiten satisfacer las consideraciones pedagógicas. El documental, compro-metido

Posgrado y Sociedad Vol. 10 No. 2 Año. 2010 con la veracidad, está urgido de su uso extensivo en el ámbito académico. Una vez que no sólo sea herramienta de exposición de contenidos sino también canal de retorno, se completará un ciclo fundamental para una educación que fomente la creación de conocimiento.

La diversidad es una constante del quehacer humano. Lograr que se genere una exposición audiovisual mucho más plural es sumamente deseable en la medida que se podrá hacer un recuento más fidedigno del mundo. No se impone una verdad, sino que se presenta una colección de miradas e interpretaciones sobre esa verdad para que los espectadores puedan elaborar sus propias posiciones. Acercar esta posibilidad a las universidades y centros académicos, favorece que los mismos elaboren materiales que promuevan la búsqueda del conocimiento y rompan con el adoctrinamiento.

Banana-Express hace un ejercicio de esta opción brindada por el animadoc. En el marco de una tesis de maestría, con escaso presupuesto $\mathrm{y}$ personal, se desarrolla una producción que cumple con los estándares de transmisión, pero para ello no debe comprometerse financieramente de manera que se constriña su posibilidad expresiva. Es decir, el relato adquiere libertad creativa. Esta modalidad aprovecha como referente, no como limitante, hechos reales y dibuja la impresión que le causan al creador de la obra.

El animadoc no viene a cuestionar la necesaria referencialidad del documental. Tan sólo la circunscribe a su interacción directa con los procesos de abstracción humanos. Al hacerla evidente, la utiliza como herramienta discursiva. Invita con esto a la criticidad de lo propuesto. En la

ISSN 1659-178X 
aceptación de su subjetividad promueve a espectadores a crear sus propios discursos. En el cumplimiento con lo factual, a su vez, promueve la veracidad argumentativa. En el reconocimiento de la existencia y la exposición de un mundo interpretativo propio de cada individuo (cinéma-vérité del pensamiento), acepta y aboga por un mundo donde quepan muchos mundos.

\section{Referencias}

Agramonte, A. (1966). Cronología del cine cubano. La Habana: Ediciones ICAIC.

Anónimo. (1947). The Press: I'll Furnish the War. Time. Recuperado el 26 de agosto de 2010, de http://www.time.com/time/magazine/article/o,9171,854840,00.html.

Anónimo. (2010). Cisco Visual Networking Index: Forecast and Methodology, 2009-2014. Recuperado el 30 de agosto de 2010, de http://www.cisco.com/en/US/solutions/collateral/ns341/ns525/ns537/ns705/ns827/white_paper_c11 -481360_ns827_Networking_Solutions_White_Paper.html.

Barnouw, E. (1993). Documentary: A history of the non-fiction film (2da ed. revisada). Nueva York: Oxford University Press.

Bordwell, D. \& Thompson, K. (1997). Film art: An introduction (5ta ed.). The McGraw-Hill Companies, Inc.

Capra, F. (Director). (1942-1944). Porqué Peleamos [Serie documental]. Estados Unidos: División de Servicios Especiales de la Armada de Estados Unidos

Fallas, F. (Director). (2009) Banana-Express. [Animadoc]. Alemania-Costa Rica: Universidad de Ciencias Aplicadas Ostwestfalen-Lippe y Universidad Estatal a Distancia.

Flaherty, R. (Director). (1922). Nanuk, el Esquimal [Documental]. Estados Unidos y Francia: Les Frères Revillon.

Folman, A. (Director). (2008). Vals con Bashir [Documental]. Israel y Alemania: Bridgit Folman Film Gang.

Hanley, M. S. (2007). Old school crossings: Hip hop in teacher education and beyond. New Directions for Adult and Continuing Education, 115, 35-44.

Heuer, B. P. (2007). Using popular media to build literacy. New Directions for Adult and Continuing Education, 115, 55-62.

McCay, W. (Director). (1918). El Hundimiento del Lusitania [Documental]. Estados Unidos: Universal Film Manufacturing

McKee, R. (1998). Story: Substance, structure, style, and the principles of screenwriting (1999 ed.). London: Methuen Publishing Limited.

McLuhan, M. (1964). Understanding media (2008 reimpresión). Padstow: Routledge.

Murch, W. (2001). In the blink of an eye (2 ${ }^{\mathrm{da}}$ ed.). Beverly Hills: Silman-James Press.

Nichols, B. (1991). Representing reality: Issues and concepts in documentary. Bloomington: Indiana University Press.

Stevenson, R. (Director). (1964). Mary Poppins [Musical-Animación]. Estados Unidos: Walt Disney Productions.

Vertov, D. (Director). (1929). El Hombre con la Cámara de Cine [Documental]. Unión Soviética: VUFKU.

Williams, R. (2001). The animator's survival kit. Nueva York: Faber and Faber, Inc. 


\section{Nota acerca del autor}

\section{Luis Fernando Fallas Fallas}

M.A. en Producción de Medios

Productor Audiovisual en el Programa de Producción de Material Audiovisual, Universidad Estatal a Distancia (UNED)

Su maestría fue parte del programa de becas de la UNED y se cursó entre 2007 y 2009 en la Universidad de Esbjerg y la Universidad de Ciencias Aplicadas de Ostwestfalen-Lippe

El animadoc Banana-Express está disponible para verlo en línea en el sitio de audiovisuales de la UNED o se puede solicitar directamente en las bibliotecas de la universidad

Correo electrónico: lufallas@uned.ac.cr 